\title{
The Correlation of Allergic Rhinitis with Obstructive Sleep Apnea Syndrome (OSAS) in Young Adults
}

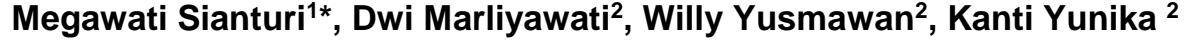 \\ ${ }^{1}$ Medical Faculty, Diponegoro University, Indonesia \\ ${ }^{2}$ Teaching Staff, Oto-RhinoLaringology Lead and Neck Department, Diponegoro University, Indonesia
}

Keywords:

Allergic Rhinitis

OSAS

Young Adults

*) Correspondence to:

sianturim77@gmail.com

Article history:

Received 29-05-2020

Accepted $25-06-2020$

Availableonline 01-07-2020

\begin{abstract}
Background: Obstructive Sleep Apnea Syndrome (OSAS) is a breathing disorder during sleep that can cause stopping breathing and trigger dangerous diseases. The main symptoms that can occur in OSAS patients are loud snoring and excessive daytime sleepiness so it can disrupt the quality of life and performance. Allergic rhinitis (AR) is one of the risk factors for OSAS, after age, obesity, gender, neck circumference, and anatomic abnormalities of the airway. Allergic rhinitis can disrupt the quality of sleep patients. Allergic rhinitis patient has a risk of OSAS due to obstruction of the upper airways, so airflow to the lungs is obstructed.

Objective: To analyse the relationship of allergic rhinitis with the incidence of Obstructive Sleep Apnea Syndrome (OSAS) in young adults.

Methods: This study is an observational study with a cross-sectional design. Samples were obtained with a probability sampling method by consecutive sampling. The subject of this study were students of the Faculty of Medicine, Diponegoro University, aged 18-23 years. This study consisted of interviews, BMI examination, neck circumference examination, nose, and throat examination, fill the Epworth Sleepiness Scale (ESS) questionnaire to assess OSAS and the Score For Allergic Rhinitis (SFAR) questionnaire to assess allergic rhinitis. Statistical tests use chisquare, fisher's exact test, and logistic regression.

Results: The incidence of allergic rhinitis with OSAS in young adults occurred as much as $79,7 \%$. Bivariate analyse showed allergic rhinitis associated significantly with the incidence of OSAS in young adults $(\mathrm{p}=0,000 ; \mathrm{PR}=12,3)$. The most common group of allergic rhinitis symptoms in allergic rhinitis patients with OSAS is the group of symptoms of sneezing, rhinorrhea, and nasal congestion.
\end{abstract}

Conclusion: Allergic rhinitis patients risk 12,3 times more likely to suffer from OSAS than non-allergic rhinitis in young adults.

DIMJ, 2020, 1(1), 21-25 DOI: https:/ / doi.org/10.14710/dimj.v1i1.7930

\section{Introduction}

Obstructive Sleep Apnea Syndrome (OSAS) is a sleep disorder that is characterized by repeated episodes of narrowing and partial or total airway obstruction. ${ }^{1,2}$ The main symptoms that can occur in OSAS patients are loud snoring and excessive daytime sleepiness so it can disrupt the quality of life and performance. ${ }^{1,3}$

Some risk factors that can cause OSAS are obesity, age, neck circumference, and anatomic airway abnormalities., ${ }^{4,5}$ OSAS is associated with metabolic and cardiovascular disorders such as diabetes mellitus, hypertension, congestive heart failure, and stroke. However, several studies have shown that OSAS can occur in people with allergic rhinitis due to nasal obstruction which causes recurring upper airway obstruction, so airflow to the lungs is obstructed. ${ }^{6}$

A study conducted by Desiderio in four geographic regions of the world found the results of the prevalence of allergic rhinitis $15-25 \%$ with $69.23 \%$ of participants expressed an increase in allergic rhinitis. This happens because of an increase in exposure to allergens, irritants, and pollutants. The survey results also said that of the $15-25 \%$ prevalence of allergic rhinitis, most experienced by children and young adults. ${ }^{7}$ An increase in the prevalence of allergic rhinitis will risk an increase in OSAS and there is still little research on allergic rhinitis with OSAS in young adults makes researchers interested in conducting researching on whether there is a relationship 
between allergic rhinitis with the incidence of OSAS in young adults.

\section{Method}

This study is an observational study with a cross-sectional approach. Samples were obtained with a probability sampling method by consecutive sampling. The subject of this study were students of the Faculty of Medicine, Diponegoro University, aged 18-23 years.

This study consisted of interviews, BMI examination, neck circumference examination, nose, and throat examination, fill the Epworth Sleepiness Scale (ESS) questionnaire to assess OSAS and the Score For Allergic Rhinitis (SFAR) questionnaire to assess allergic rhinitis. Before collecting data, the author explained to subjects about the aim of this study. Subjects were then asked to give consent regarding involvement in a study by signing informed consent. The author proceeded with checking the questionnaires and analyzed the collected data. From 134 research subjects, there were 100 samples that fit the inclusion criteria.

Inclusion criteria in this study were students of the Faculty of Medicine, Diponegoro University batch 2016-2018, aged 18-23 years old, compos mentis, willing to be involved in this study and sign an informed consent, BMI normal, and neck circumference less than $40 \mathrm{~cm}$. Exclusion criteria in this study were Active smoker, hypertrophy concha, nasal polyps, tonsillar hypertrophy, rhinosinusitis, asthma, and high mallampati score (III-IV).

Data were analyzed using chi-square, fisher's exact test, and logistic regression.

\section{Result}

Age, sex, allergic rhinitis, OSAS, septum deviations, of allergic rhinitis with OSAS, septum deviations with OSAS are described in table 1.
Table 1. Characteristics of Respondents

\begin{tabular}{lcc}
\hline Variable & Frequency & $\begin{array}{c}\text { Percentage } \\
(\%)\end{array}$ \\
\hline Age (years old) & 2 & 2 \\
18 & 14 & 14 \\
19 & 27 & 27 \\
20 & 48 & 48 \\
21 & 9 & 9 \\
22 & & \\
Gender & 87 & 87 \\
Female & 13 & 13 \\
Male & & \\
Allergic Rhinitis & 62 & 62 \\
Yes & 38 & 38 \\
No & & \\
OSAS & 64 & 64 \\
Yes & 36 & 36 \\
No & & \\
Deviated Septum & 13 & 13 \\
Yes & 87 & 87 \\
No & & \\
Allergic Rhinitis with & & 51 \\
Deviated Septum & 51 & 49 \\
Yes & 49 & 100 \\
No & 100 & \\
\hline Total & & \\
\hline
\end{tabular}

The highest respondents in this study were 21 years old with a total of 48 people $(48 \%)$ and the lowest respondents were 18 years old totalling 2 people $(2 \%)$. Based on the examination conducted on 100 respondents, found 62 respondents with allergic rhinitis (62\%), 64 respondents with OSAS (64\%), 13 respondents with the deviated septum $(13 \%)$, and 6 respondents suffered from allergic rhinitis with the deviated septum (6\%). In this study, $87 \%$ of respondents were female.

Table 2. Distribution of Symptoms of Allergic Rhinitis

\begin{tabular}{lcc}
\hline \multicolumn{1}{c}{ Symptoms } & Frequency & Percentage \\
\hline Sneezing, & 33 & 64,7 \\
Rhinorrhea, Nasal & & \\
$\begin{array}{l}\text { Congestion } \\
\text { Sneezing, Rhinorrhea }\end{array}$ & 8 & 15,7 \\
$\begin{array}{l}\text { Sneezing, Nasal } \\
\text { Congestion }\end{array}$ & 4 & 7,8 \\
$\begin{array}{l}\text { Rhinorrhea, Nasal } \\
\text { Congestion }\end{array}$ & 1 & 2,0 \\
Nasal Congestion & 5 & 9,8 \\
\hline Total & 51 & 100
\end{tabular}

Table 2 shows the most group of symptoms allergic rhinitis experienced by allergic rhinitis patients with OSAS is a group of symptoms of sneezing, runny nose, and nasal congestion with 33 respondents $(64.7 \%)$. In contrast the lowest allergic rhinitis symptom group experienced by allergic rhinitis sufferers with OSAS is a group of 
rhinorrhea and nasal congestion as many as 1 respondent $(2 \%)$.

Table 3. Correlation between allergic rhinitis, deviated septum, gender, with OSAS

\begin{tabular}{|c|c|c|c|c|c|c|c|c|c|c|}
\hline \multicolumn{2}{|c|}{ Variable } & \multicolumn{2}{|c|}{ OSAS } & \multicolumn{2}{|c|}{ Non-OSAS } & \multicolumn{2}{|c|}{ Total } & \multirow[t]{2}{*}{$\mathbf{P}$} & \multirow[t]{2}{*}{ PR } & \multirow[t]{2}{*}{ IK 95} \\
\hline & & $\mathrm{N}$ & $\%$ & $\mathrm{n}$ & $\%$ & $\mathrm{~N}$ & $\%$ & & & \\
\hline \multirow{2}{*}{ Allergic Rhinitis } & Yes & 51 & 79,7 & 11 & 30,6 & 62 & 62 & 0,000 & 8,9 & $3,501-22,705$ \\
\hline & No & 13 & 20,3 & 25 & 69,4 & 38 & 38 & & & \\
\hline \multicolumn{2}{|l|}{ Total } & 64 & 64 & 36 & 36 & 100 & 100 & & & \\
\hline Deviated & Yes & 11 & 17,2 & 2 & 5,6 & 13 & 13 & 0,127 & 3,528 & $0,376-16,908$ \\
\hline Septum & No & 53 & 82,8 & 34 & 94,4 & 87 & 87 & & & \\
\hline \multicolumn{2}{|l|}{ Total } & 64 & 64 & 36 & 36 & 100 & 100 & & & \\
\hline \multirow[t]{2}{*}{ Gender } & Female & 58 & 90,6 & 29 & 80,6 & 87 & 87 & 0,215 & 2,333 & $0,718-7,578$ \\
\hline & Male & 6 & 9,4 & 7 & 19,4 & 13 & 13 & & & \\
\hline \multicolumn{2}{|l|}{ Total } & 64 & 64 & 36 & 36 & 100 & 100 & & & \\
\hline
\end{tabular}

"Significant $(\mathrm{p}<0.05)$

There are 64 study samples suffer from OSAS and 51 samples $(79.7 \%)$ of them suffer from allergic rhinitis with OSAS. In non-allergic rhinitis, the incidence of OSAS occurred in $13(20.3 \%)$. Based on the chi-square test results obtained a significant correlation between allergic rhinitis and the incidence of OSAS in young adults $(\mathrm{p}=0.000)$ and no significant relationship between septum deviation and gender with OSAS in young adults ( $\mathrm{p}$ $=0.127 ; \mathrm{p}=0.215)$. $($ Table 3$)$

\section{Multivariate analysis}

Table 4. Multivariate of allergic rhinitis, deviated septum, and gender

\begin{tabular}{clccc}
\hline Stages & Variable & P & PR & IK 95\% \\
\hline 1 & Allergic & 0,000 & 12,013 & $4,263-$ \\
& Rhinitis & & & 33,853 \\
& Deviated & 0.011 & 10,870 & \\
& Septum & & & $1,718-$ \\
& Sex & 0,148 & 3,083 & 68,800 \\
& & & & $0,671-$ \\
2 & & & & 14,161 \\
& Allergic & 0,000 & 12,334 & $4,422-$ \\
& Rhinitis & & & 34,403 \\
& Deviated & 0,017 & 8,342 & \\
& Septum & & & $1,454-$ \\
& & & & 47.859 \\
\hline
\end{tabular}

* Logistic Regression Test

Table 4 shows the results of multivariate analysis with logistic regression tests to determine the relationship of allergic rhinitis, septum deviation, and gender. The results show that allergic rhinitis and septal deviation have a significant relationship with the incidence of OSAS. People with allergic rhinitis and septal deviation have a 12.3 and 8.3 times greater risk of developing OSAS.

\section{Discussion}

This study analyses the relationship of allergic rhinitis with the incidence of OSAS in young adults and obtains significant results between allergic rhinitis and the incidence of OSAS. These results are consistent with research conducted by Firdaus which also shows a significant relationship between allergic rhinitis and OSAS. ${ }^{8}$ Research conducted by Young states that respondents who experience symptoms of rhinitis at night significantly experience snoring and excessive daytime sleepiness which is the most common symptom of OSAS. ${ }^{9}$ In this study, there were 64 samples suffered from OSAS and 51 of them suffered from allergic rhinitis with OSAS (79.7\%). Research conducted by Zheng shows that the prevalence of allergic rhinitis occurs $27 \%$ in OSAS patients. ${ }^{10}$ This shows that the incidence of OSAS in people with allergic rhinitis is quite high.

Based on the group of symptoms of allergic rhinitis, the most group of symptoms experienced by allergic rhinitis patients with OSAS is a group of symptoms of sneezing, rhinorrhea, and nasal congestion. Previous studies have shown that the most common group of symptoms of allergic rhinitis is rhinorrhea and nasal congestion. ${ }^{11}$

A study conducted by Craigs stated that rhinorrhea and nasal obstruction are very influential on the quality of sleep because these symptoms can result in increased airway resistance which results in nasal cavity obstruction. ${ }^{12}$ In allergic rhinitis, there is an increase in inflammation mediators such as histamine, IL-1 $\beta$, IL-4, and CysLTs that cause sleep disturbances, inflammation in the nose and nasal obstruction. ${ }^{13,14}$ Nasal obstruction and rhinorrhea that occurs in allergic rhinitis will cause someone to breathe through the mouth (mouth 
breathing). When the mouth is opened, the mandible moves downwards, further displacing the tongue in that direction. this causes a decrease in the diameter of the upper airway musculus dilator and a decrease in pharyngeal diameter, both of these conditions will cause obstruction or the cessation of airflow in the mouth breathing and will result in OSAS. ${ }^{13}$

This research has confounding variables which are deviated septum and sex. The results showed the deviation of septum had a significant relationship with the incidence of OSAS while the sex did not have a significant relationship with OSAS. The results of this study are consistent with the results of previous studies conducted by Jinesh, which showed a significant relationship between the septum deviation with OSAS. ${ }^{15}$ Septum deviation will obstruct the nose which causes an increase in resistance to airflow, which can lead to sleep disturbance and OSAS. ${ }^{16}$

\section{Conclusion}

Allergic rhinitis has a significant relationship with the incidence of OSAS in young adults with the most symptoms of allergic rhinitis that is experienced is sneezing, runny nose, and nasal congestion.

\section{Ethical Approval}

Ethical clearance was obtained from Research Ethics Commission Medical Faculty Diponegoro University with the number of 254/EC/KEPK/FKUNDIP/VI/2019.

\section{Conflicts of Interest}

The authors declare no conflict of interest.

\section{Funding}

No specific funding was provided for this article.

\section{Author Contributions}

Writing-original draft preparation, Megawati Sianturi; writing-review and editing, dr. Kanti Yunika, Sp. THT-KL, dr. Dwi Marliyawati, M.Si.Med, Sp. THT-KL

\section{Acknowledgments}

This work was supported by Department of Oto-RhinoLaringology Lead and Neck, Faculty of Medicine, Diponegoro University.

\section{References}

1. Rezaeitalab F, Moharrari F, Saberi S, Asadpour H, Rezaeetalab F. The correlation of anxiety and depression with obstructive sleep apnea syndrome. J Res Med Sci. 2014;19(3):205-10.

2. Carter SG, Carberry JC, Eckert DJ. Obstructive sleep apnea: current perspectives. Nat Sci Sleep J. 2018;10:2134.

3. Morinaga Y, Matsumura K, Kansui Y, et al. Impact of obstructive sleep apnea on blood pressure and cardiovascular risk factors in Japanese men: A cross-sectional study in work-site group. Clin Exp Hypertens. 2017;00(00):1-6.

4. Fusun A. Allergic and nonallergic rhinitis : the threat for obstructive sleep apnea. Ann Allergy Asthma Immunol. 2009;103:20-5.

5. Hs MR, Yogiarto M. Obstructive Sleep Apnea ( OSA ). J Ilm Kedokt. 2015;2(3):924.

6. Zheng M, Wang X, Ge S, et al. Allergic and Non-Allergic Rhinitis Are Common in Obstructive Sleep Apnea but Not Associated With Disease Severity. J Clin Sleep Med. 2017;13(8):959-66.

7. Passali D, Cingi C, Staffa P, Passali F, Muluk NB, Bellussi ML. The International Study of the Allergic Rhinitis Survey: outcomes from 4 geographical regions. Asia Pasific Allergy. 2018;8(1):1-15.

8. Firdaus D intan. Hubungan rinitis alergi dan obstruktif sleep apneu pada mahasiswa fakultas kedokteran universitas muhammadiyah malang angkatan 20112012. 2013;0:133-35.

9. Koinis-mitchell D, Craig T, Esteban CA, Klein RB. Sleep and allergic disease: A summary of the literature and future directions for research. $J$ Allergy Clin Immunol. 2012;130(6):1275-81.

10. Zheng M, Wang X, Zhang L. Association between allergic and nonallergic rhinitis and obstructive sleep apnea. Curr Opin Allergy Clin Immunol. 2017;17.

11. Setiawan I. Hubungan Rinitis Alergi Dan Obstruktif Sleep Apneu Di Poli THT RS Universitas Muhammadiyah Malang. 2015;11(2):133-5.

12. Sardana N, Craig TJ. Congestion and Sleep Impairment in Allergic Rhinitis. Asian $J$ Pharm Heal Sci. 2011;29:297-306.

13. Chirakalwasan N, Ruxrungtham K. The 
linkage of allergic rhinitis and obstructive sleep apnea. Asian Pac J Allergy Immunol. 2014;32:276-87.

14. Tashiro M, Mochizuki H, Iwabuchi K, Sakurada Y. Roles of histamine in regulation of arousal and cognition: functional neuroimaging of histamine $\mathrm{H} 1$ receptors in human brain. Life Sci. 2002;72:409-14.

15. Shah JA. Obstructive Sleep Apnea : Role of an Otorhinolaryngologist. Indian $J$ Otolaryngol Head Neck Surg. 2016;68(1):71-4.

16. Kohler M, Bloch KE, Stradling JR. The role of the nose in the pathogenesis of obstructive sleep apnea. J Otolaryngol Head Neck. 2009:33-7. 